\title{
Principle "Understanding” from Perspective of Linguistic Investigations
}

\author{
E. V. Bobyreva \\ Theory of English department \\ Volgograd State Socio-Pedagogical University \\ Volgograd, Russia \\ new_life@mail.ru \\ M. R. Zheltukhina \\ Theory of English department \\ Volgograd State Socio-Pedagogical University \\ Volgograd, Russia \\ zzmr@mail.ru
}

\author{
O. A. Dmitrieva \\ Theory of English department \\ Volgograd State Socio-Pedagogical University \\ Volgograd, Russia \\ dmoa@yandex.ru
}

\author{
M. V. Busygina \\ English Language and Methods of its Teaching department \\ Volgograd State Socio-Pedagogical University \\ Volgograd, Russia \\ busygina_maryana@mail.ru
}

\begin{abstract}
This article is aimed at investigation of the principle of "understanding" within linguistic reflection. Understanding is connected with interpretation of the context and knowledge of the interpreter, which is socially determined. Expediency of the discourse approach to studying the principle of text "understanding" is set and peculiarities of understanding in different types of discourse are shown. It is established that the cognition refers to psychic phenomenon and represents a method of social and humanitarian understanding and an integral component of social life, practical skill connected with social life. Understanding discourse is based on two constituent parts text's properties and specifics of linguistic personality. Understanding is also viewed from the point of view of its fullness (complete understanding and incomplete understanding). In the article, factors determining the possibility and effectiveness of speech influence are revealed: linguistic and extralinguistic (semiotic, social, cognitive, psychological) factors.
\end{abstract}

Keywords - understanding; misunderstanding; comprehension; incomprehension; cognition; discourse; linguistics; influence, language; language personality.

\section{INTRODUCTION}

"When I speak and I am understood I don't fully shift ideas from my head into the head of another person - as the flame of a candle doesn't crush when I lit another candle from it because in each candle its own gases are inflamed" (A.A. Potebnya) [1, p. 225-226]. Analysis of the processes of speech perception and producing including experimental investigation of psychological activity of a person on learning and usage of the language as organized and autonomous system is done by psycholinguistics. In pragmatic aspect, speech utterance is treated as a unit of communication determined by the requirements of communication as well as by social and historical context of the language functioning. In cognitive linguistics, speech and speech activity are understood as a form of processing information (which is encoded by language means), as a cognitive process. Perception of the surrounding world specific for each particular language group is being reflected in speech activity of this group of people and is recorded in the language in the form of concepts, notions, ideas and opinions, which are expressed in different utterances-judgments.

\section{LITERATURE REVIEW AND METHODS OF RESEARCH}

The problem of understanding which takes one of the key positions in philosophical, psychological and linguistic science was considered in the context of exegesis (Greek: exegesis interpretation) and was connected with the interpretation of ancient texts, mainly religious. More general theory of interpretation and understanding - hermeneutics (from Greek hermeneutike (techne) - interpretational (art)) began to form in the previous century thanks to scientific research of $F$. Schleiermacher and V. Dilthey. Let us enumerate the names of only few scientists, which devoted their scientific activity to the problem of understanding. Within the philosophy understanding was considered by N.S. Avtonomov, R. Barthes, M.M. Bakhtin, P. Berger, E. Betti, G. Gadamer, P.P. Gaydenko, A. Husserl, W. Dilthey, M.K. Mamardashvily, M. Polanyi, P. Ricoeur, H. Rickert, V.G. Fedotov, J. Habermas, G.I. Tsintsadze, F. Schleiermacher and others.

Within sociology understanding was studied by M. Weber, Y. Cassirer, F. Nitshe, G. Rickert, M. Shreyder, S. Freud. Taking into account position of M. Haideger, who focuses his attention on linguistic nature of genesis it becomes evident that "Genesis is the language". Thus, one exists within the language and the things do not exist until they get their names. Therefore, reality is within the language [2, p. 114]. This position is shared by modern philosophers who pay attention on textualization of cognition that is on understanding the 
world as a text. Within linguistics B.U. Babushkin, M.M. Bakhtin, V.S. Gorskiy, A.A. Potebnya, and V.M. Sokovnin investigated problem of understanding (with the position of communicative aspect). Apriori, language is the basis of understanding because it embodies thought and allows transmitting it in the process of communication. Reification happens through semiotic system in which language presents a type of a sign system. Thus, language presents an object of cognition. Accordingly, text is "a fact of objectification of cognition, intention to be transmitted to somebody and it exists only in the perception of a person who receives it, reads it and understands" [3]. V.G. Afanasiev, V. Dilthey, A.N. Leontiev, S.A. Rubinshtein analyzed cognition from the position of individual-psychological aspect. Cognition refers to psychic phenomenon and represents not only a method of social and humanitarian understanding but also an integral component of social life, practical skill connected with social life. In the process of socialization, a fundamental system of meanings is constructed and within its borders all phenomena of social life - situations and circumstances, actions of other people and their reasons - are understood [4]. According to V.Z. Demiankov "Cognition (understanding, comprehension; Verstehen, Verständigung; comprehension, entendement) cognitive activity (a type of speech activity) a result of which is to determines the sense of some object (a text or a discourse as a rule)". A scholar points out the following modules of understanding: 1. Use of knowledge of the language. 2. Construction and verification of hypothetical interpretations. 3. Assimilation of what is said. 4. Reconstruction of the author's intentions. 5. Establishing of the degree of divergence between inner and model worlds. 6. Establishing of connections within model and inner worlds: a field of tension within model and inner world is constructed (the third module relies on the result of the solution of this problem). 7. Correlation of model world with direct perception of reality. 8 . Correlation with a line of behavior. 9. Choice of a "tone" or a "key" [5, p. 125]. Enumerated modules allow coming out of the narrow approach to interpretation of understanding because, besides traditional look at understanding - as detection of the meaning of the text, it gives an opportunity to study extralinguistic characteristics and to move from text to discourse.

\section{RESULTS AND DISCUSSION}

Discourse being a text immersed in life, can be studied from the point of view of two approaches: objective and subjective. And let us follow the position of V.I. Karasik who believes that the essence of the objective approach is in thematic ranking of discourses wherein political, gastronomic, medical, religious discourse are distinguished. Subjective approach involves analysis of communicative situation and its constituents (participants, chronotop, aim, genres, strategies and tactics, discursive formulae). Advantage of this approach is integration of the achievements of such humanitarian sciences as sociology, psychology, history, cultural science, ethnography and philology [6, p. 259-261], and that is, from the authors' point of view, extremely important for cognition investigation. So studying a text as a structural element of discourse is provided by the activity-communicative approach when social communication is a source of situations of interpreting and cognition of language actions and types of discourse in general. Win this case, cognition happens to be not a state of consciousness and not a mean of transformation of one of its condition into another but a mean of finding a way out of a situation of misunderstanding. In this case, the problem of definition of active bases of transition from misunderstanding to understanding comes forward [7]. From the point of view of O.B. Soloviev understanding is opposed to misunderstanding which is characterized by such properties as degree and types of misunderstanding as well as nature of misunderstanding [8]. There are different typologies of understanding, for example, according to the fullness of later superficial, incomplete, incorrect understanding and misunderstanding, etc. are distinguished. In its turn, understanding is assimilation of knowledge and taking into account four pointed above types of knowledge the following types of understanding can be distinguished: recognition corresponds to superficial understanding; enlightenment and perception correspond to deep comprehension (knowledge) [9]. There is a point of view according to which understanding presents a norm, and misunderstanding is a violation of norm. But such position seems to be simplified because expression "to speak different languages" which is reflected in the language points not to the chosen language as it is to the discrepancy of the life views of the participants of communication, which did not come to any agreement in the process of communication - "did not understand each other".

Taxonomy of understanding on the basis of cognitive characteristic is also suggested in linguistics. For example, G.I. Bogin points out semantizing understanding, that is "decoding" of the units of the text which perform a sign function. Such understanding can be found when conceptual comprehension of the text is broken during the language studying process. For example, in the situation when among 'well-known words', one has come across 'an unknown one', which must be explained (semantized). Cognitive comprehension which arises when one needs to overcome certain difficulties during assimilation of the content of cognitive information which is presented in the form of the same text units which confront semantizing understanding; it is possible to point out dissemantizing understanding [10].

Incomplete understanding happens when participants of communication strive for maximum understanding, which is determined by the type of communication, for example in medical discourse.

The aim of medical discourse is to diagnose the disease and treat the patient. Accordingly, in the process of communication between a doctor and a patient there is an exchange of information which is maximally explicit, in case of misunderstanding additional questions are asked, though communication within medical discourse is surface. There might be mistakes but they are easily detected and corrected and in doing so such tactics as asking back, repeated question, using synonyms are used and that helps to make the understanding process easier. Within the borders of this institutional discourse the personality is not identified, participants of communication play certain social roles, which are prescribed by medical discourse itself: doctor - patient. Semantized understanding is possible in this case, because on 
the level of familiar text, some terms can be used and their decoding can be difficult: stenosis, hysteroscopy, atherosclerotic lesions.

Full understanding is possible only during deep communication, empathy, when participant of communication must put himself in a position of a person he interacts with. In these conditions, personality is revealed and misunderstanding can be accompanied with negative emotions: worrying, disappointment, sadness. Misunderstanding in this type of communication has a personal character and to certain extent depends on the mood of the participants of communication, for example in one case both participants can be reveled and in another case only one of them can be revealed.

Misunderstanding can vary and be built into communication and it can occur either at the beginning or in the middle of it. In this case, it can be a mean to achieve understanding, or it can occur at the final stage of communication and then it happens to be unproductive formation and it presents the result of communication [11, p. 36].

It is important to take into account social significance of the textldiscourse comprehension. Thus, speaking about spiritual security it is relevant to point out the importance of comprehension of religious texts because a priori, they can be referred to the system of norms of social interaction of members of society and they regulate values and behavior of people. Misunderstanding of religious texts can lead to disunity, dissent and extremism.

Overall, one can see that speaking about understanding within discourse it is advisable to point out two systemforming, interconnected and interdependent concepts: text and linguistic personality. The first concept is based on understanding of the text and accordingly one can point out such characteristics as completeness, coherence, stylistic unity, integrity of the text. In addition, the second block is connected with linguistic personality and includes a component of value (world outlook), a component of culture and a component of personality (individual, deep). Thus, degree to which a text is understood is defined by many characteristics, herewith in some cases misunderstanding of the text with some structural violations can happen as a result of linguistic personality's incompetence.

In the century of globalization, one faces the total informatization of space and that happens due to the active use of mass media to realize the goals of providing information and impact on the addressee, which are set by the addresser. In addition, in this respect problem of understanding of the flows of information and addressee's intensions becomes especially important as one is talking about a mass addressee.

The following factors determining the possibility and effectiveness of speech influence can be pointed out:

1. Linguistic - interpretative factor of variable reflection of reality which manifests itself in the lexical sphere and is based on the mechanisms of verbal impact on the consciousness: quasi-synonymy, deliberate ambiguity, "ideological connectedness", connotative shades of meaning, etc.; explicitness and implication of the content plan: placement of the component of meaning which is important for the addressee to the implicit layer of the utterance [12-17].

2. Extralinguistic - factor of social need for information with all semiotic, mental, ethnocultural, social, cognitive and other characteristics of a person's life.

1) Semiotic - the idea about significant variation of language expressions ("critical linguistics" of R. Fowler [18]) in accordance with installations, claims, aims, coincidence (identical understanding of an addresser and addressee, notideological) and difference of the views on language variants of a thing or phenomenon designation (awareness of the addresser and unawareness of the addressee, ideological, powerful; unawareness of the addresser and awareness of the addressee), awareness and correction of the choice of the participants of communication - verbal strategies in dialogue.

2) Social - choice and dosage of the information, correlation of negative and positive details (for example, praise seems most likely with the elements of criticism, criticism - with positive assessment), knowledge and taking into account stereotypes and myths of mass consciousness, orientation for "We-group", authoritarian statements [19-21].

3) Cognitive - process of information processing by a person [22-23]: passivity of perception, errors in assessment of evidence, mistakes in perception of false causal connections relations - it all leads to inadequate reflection of reality. Speech activity - is one of the means of acquiring knowledge and world cognition. Language ability - presents the top of an iceberg the basis of which is formed with such cognitive abilities as presentation of images, logical conclusion on their basis, acquiring new knowledge based on that received previously, preparation and execution of plans [24]. When basic categories of speech impact are described it is necessary to explicit the connections of language expression with the structures of knowledge and procedures of their processing.

Heterogeneity of a content plan stipulates the transition to the linear representation of non-linear, packed [25] cognitive structure where some of its parts are implicit (presuppositions, prescriptions, consequences, illocutionary components, etc.) and lead to manipulations. Experience of the situations' standardization ritualizes person's cognition and behavior, is reflected in his speech stereotypes, and enables to prognosticate his possible speech strategies and tactics. Since the essence of communicative rules is constant violation of the former it is of a special scientific interest to investigate nonstandard examples of usage and their interpretations not as mistakes but as specific operations with knowledge with the purpose of the intentional complication of the communicative process (communicative failure, communicative misuse) [26].

4) Psychological - emotional speech impact on the addressee: a) persuasion (logical arguments) - reliance on consciousness, reason, b) suggestion (emotional arguments) appeal to emotions and bringing the addressee to a psychological condition desirable for the addresser's purposes. Emotional impact can be explained through the current setups, unconscious readiness of a person to a certain reaction, his modus, overall condition, and it influences the creation of new 
setups and stereotypes as firmly rooted attitude to homogeneous and similar phenomena, correction of values.

Speech interaction presents constant process of matching the interests of addresser and addressee as well as the interests of emerging community during which the process of speech communication is created and it has vertical (extension, domination, subordination), horizontal (interpersonal distance), spatial and temporal dimensions which determine the character of psychological communicative contact.

As a result of conducted research the following factors of informational influence of mass media and mass communication on the addressee's consciousness have been defined [27-31]:

1) linguistic - mechanisms of speech influence on the addressee's consciousness and sub-consciousness;

2) extralinguistic - mechanisms of speech influence in conjunction with different factors:

a) semiotic - uncontrolled and non-digestible excessiveness;

b) social - censorship (from the government and massmedia owners) and self-censorship (from mass-media) incompleteness, necessity to preserve secrecy of a particular information and stability of the systems of its dissemination and storage (in the military-technological sphere, in the sphere of strategic and commercial "know-how", and in the sphere of personal security);

c) cognitive - inadequate character of reality (shifting or falsity of information), counter-cultural shock (destruction of the addressers' consciousness), manipulative orientation;

d) psychological - preset evaluation (labels instead of facts), conflict inconsistency, inadequate character of perception by the addressees (both by individual and mass).

\section{CONCLUSION}

In other words, one of the peculiarities of understanding is its active character that is the volitional effort of a linguistic personality (addressee of communication) is required, because the addressee makes a choice from many available options. Understanding is connected with interpretation of the context and knowledge of the interpreter, which is socially determined. Treatment of the understanding as the process of interpreting expresses the vision that in the process of understanding it is necessary not only to understand units of the language but also to find out what is hidden behind them [32, p. 25]. From the authors' point of view, such position itself justifies discourse approach to text studying.

Discovered linguistic and extralinguistic factors determine psychological view on influence, which is treated in psychology as deliberate transformation of motion and information from one participant of interaction to another. In the $21^{\text {st }}$ century, humanity is in the phase of oversaturation of informative space and informative pressure, so mass media discourse has a huge impact on public consciousness. Most ideas and knowledge about the world are formed inside a person under the influence of such mass media channels as
$\mathrm{TV}$, radio, press, Internet. Herewith the text of mass media solves the basic psychological problems: to attract attention to it, to optimize its perception, to make perception of its content by the addressee easier.

Thus, understanding within discourse varies from full understanding to complete misunderstanding. Depending on the stage of communication, misunderstanding presents either a non-productive result or a mean to achieve understanding. Understanding in every-day discourse is marked with emotional component. Understanding in institutional types of discourse does not have a personal character, though it is connected with some behavioral stereotypes. Understanding of discourse is based on two constituents: characteristics of text and linguistic personality.

\section{References}

[1] A.A. Potebnya, Complete collection of works: Thought and language, Moscow: Labyrinth, 1999, 300 p.

[2] V.I. Medvedev, "Understanding and explanation in humanitarian and natural-science cognition", dissertation ... Dr., philology. St.Petersburg, 1998,359 p.

[3] I.A. Tretiakova, "Principle of "understanding" in humanitarian cognition," in Works of St.Petersburg State University of culture and art. vol. 190, 2010, pp. 112-115.

[4] E.S. Kubriakova, V.Z. Demiankkov, Y.G. Pankrats, L.G. Luzina, "Understanding", in Short Dictionary of cognitive terms, Under the general editorship of E.S. Kubriakova. Moscow: Philological Department of Moscow State University named after M.V. Lomonosov, 1996, pp. 124-126.

[5] E.A. Beltseva, "Ontology and theory of cognition," dissertation .... Ph.D., philology. Kirov, $2003 . \quad$ // URL: http://cheloveknauka.com/problema-ponimania-v-gumanitarnompoznanii (date of access 09/14/2016).

[6] V.I. Karasik, "Language spiral: values, signs, motives," Volgograd: Paradigma, 2015, $432 \mathrm{p}$

[7] E.L. Kutsova, "Genesis of cognition as a cultural function of the language": dissertation .... Ph.D, philosophy. Rostov-on-Don, 2007, $188 \mathrm{p}$.

[8] O.B. Soloviev, "Reflexive mechanisms of sociocultural dynamics of cognition," thesis of the dissertation ... Dr., philology. Novosibirsk, 2009, 33 p.

[9] V.I. Karasik, Language crystallization of sense, Volgograd: Paradigma, 2010, 428 p.

[10] G.I. Bogin, Acquiring the ability to comprehend: introduction to philological hermeneutics, Moscow: Psychology and Business on-line, 2001, 516 p.

[11] U.V. Lushnikova, "Linguavocative investigation of the situation of misunderstanding in texts of V.M. Shukshin's stories," dissertation ... Ph.D., philology. Gorno-Altaysk, 2003, 190 p.

[12] R.M. Blakar, "Language as the tool of the social power", in Language and modeling of social interaction, Moscow: Progress, 1987, p. 88-125.

[13] H. Weinrich, "Lie Linguistics", in Language and modeling of social interaction, Moscow: Progress, 1987, pp. 44-88.

[14] T.N. Nikoleva, "Linguistic demagogy" in Pragmatics and problems of an intensionality, Moscow: IL AS USSR, 1988, pp. 154-165.

[15] N.A. Kupina, Totalitarian language: Dictionary and speech realization, Yekaterinburg-Perm: ZUUNTs, 1995, 143 p.

[16] E.V. Paducheva, Semantic researches, Moscow: School of "Language of the Russian culture," 1996, 464 p.

[17] V.I. Karasik, Language circle: personality, concepts, discourse, Volgograd: Peremena, 2002, 477 p.

[18] R. Fowler, R. Hodge, G. Kress, T. Trew, Language and Control, London etc.: Routledge a. Kegan Paul, 1979, 224 p. 
[19] S. Povarnin, "Dispute. About the theory and practice of the dispute," in Philosophy Questions, 3, 1990, pp. 60-137.

[20] N.N. Troshina, "Stylistic parameters of texts of mass communication and realization of communicative strategy of the subject of speech influence," in Speech influence in the sphere of mass communication, Moscow: Science, 1990, pp. 62-68.

[21] A.V. Dmitriyev, V.V. Latynov, and A.T. Hlopyev, Informal political communication, Moscow: ROSSPEN, 1997, $197 \mathrm{p}$.

[22] A.N. Baranov, and P.B. Parshin, "Language mechanisms of variable interpretation of reality as means of influence on consciousness," in Language role in mass media, Moscow, 1986, pp. 100-142.

[23] A.N. Baranov, and P.B. Parshin, "To creation of the dictionary of terms of cognitive science," in Cognitive researches abroad: Methods of artificial intelligence, Moscow, 1990, pp. 139-149

[24] O.S. Issers, Communicative strategy and tactics of the Russian speech. Moscow: URSS, 2002, $284 \mathrm{p}$.

[25] W. Chafe, "Memory and verbalization of last experience," in New in foreign linguistics, Issue 12, Moscow: Progress, 1983, pp. 35-73.

[26] E.V. Paducheva, "Subject of language communication in Carroll's fairy tales," in Semiotics and informatics, Issue 18, 1982, pp. 76-119

[27] M.R. Zheltukhina, L.G. Vikulova, S.V. Mikhaylova, L.A. Borbotko, and A.R. Masalimova, "Communicative Theatre Space in the Linguistic and
Pragmatic Paradigm,” in XLinguae Journal, vol. 10, Iss. 2, April 2017, pp. 85-100.

[28] M.R. Zheltukhina, V.L. Mouzykant, V.V. Barabash, E.B. Ponomarenko, E.V. Morozova, and S. Mori, "Russian and Japanese Younger Generations in Search for a New Media Product," in Man In India, 97 (3), 2017, pp. 223-236.

[29] E. Malushko, A. Novozhilova, Ye. Shovgenina, S. Korolkova, and A. Shovgenin, "Developing professional competence of a translator: information retrieval and information technology constituents", in 3nd international multidisciplinary scientific conference on social sciences \& arts SGEM 2016: conference proceedings, Book 1, vol. 1, 2016, pp. 669676.

[30] E.V. Bobyreva, I. V. Palashevskaya, Yu. V. Pogrebnyak, A. M. Morozova, and E. A. Kurchenkova, Diskursive space of the modern world, Saint-Louis, MO, USA: Publishing House Science and Innovation Center, 2014, $150 \mathrm{p}$.

[31] O.A. Dmitriyeva, "Language fashion as behavioural regulator", in Humanitarian and social sciences, 2, 2014, pp. 535-538.

[32] S.A. Andreeva, "Understanding and interpreting, significance and meaning: differentiation of notions," Bulletin of Moscow State Linguistic University, Iss. 17, 2012, pp. 21-35. 